\title{
Surface Chemistry of a Microcoated Energetic Material, Pentaerythritoltetranitrate (PETN)
}

\author{
C. M. Worley* \\ Materials Engineering Department, University of Dayton, Dayton, Ohio 45469, USA
}

M. D. Vannet, G. L. Ball and W. E. Moddeman

Monsanto Research Corporation-Mound, Miamisburg, Ohio 45342, USA $\dagger$

\begin{abstract}
A microcoating technique was used to apply a polymer to an energetic explosive material. The explosive was pentaerythritoltetranitrate (PETN), and the coating was a copolymer consisting of vinylchloride/trifluorochloroethylene in a 1.5/1.0 molecular ratio. X-ray photoelectron spectroscopy (XPS) and ion scattering spectroscopy (ISS) were used to study the surface and interfacial chemistry of PETN powders and pellets made from compressed powders having either 0.5 or $20 \mathrm{wt} \%$ coating. Two simple models were used to discuss the nature of the copolymer film on the PETN. Model I shows the copolymer completely coating PETN; Model II depicts the copolymer as only partially covering PETN. Model II was applicable in explaining the 0.5 and $20 \mathrm{wt} \%$ microcoating of powders, as well as the $0.5 \mathrm{wt} \%$ coated pellets. However, the pellets with $20 \mathrm{wt} \%$ coating showed the copolymer to completely coat PETN (Model I), suggesting copolymer redistribution during pelletization. XPS and ISS results showed the copolymer film to be thin. An XPS expression modified to accommodate ISS data was developed for the calculation of the average copolymer thickness of PETN. The thicknesses were determined to be $10 \AA$ and $6 \AA$ for 0.5 wt $\%$ coated PETN powders and pellets, respectively. Bonding between the copolymer and PETN was concluded to be mechanical.
\end{abstract}

\section{INTRODUCTION}

The material used in this study was an explosive powder, pentaerythritoltetranitrate (PETN), and the coating was a copolymer of vinylchloride/trifluorochloroethylene in a 1.5/1.0 molecular ratio. The surface and interfacial chemistry of microcoated PETN have been previously examined. ${ }^{1,2}$ The results have shown that the coatings of ethylcellulose and vinylchloride/trifluorochloroethylene are compatible for use in microating PETN. The coatings were found to be thin for less than $2 \mathrm{wt} \%$ copolymer and also showed no alteration in the physical properties of PETN after microcoating.

In this work, the surface and interfacial chemistry of microcoated PETN were extensively studied using a combination of $\mathrm{x}$-ray photoelectron spectroscopy (XPS) and ion scattering spectroscopy (ISS). XPS derives information from the surface and several layers below, whereas, ISS takes information only from the first monolayer. The combination of XPS and ISS can be used to determine the type of bonding which occurs between PETN and vinylchloride/trifluorochloroethylene and also permits the copolymer thickness to be determined.

A microcoating technique, which involved the starved addition of the copolymer to PETN in order to obtain

\footnotetext{
* Work was done in partial fulfillment for a Masters of Science Degree in Materials Engineering. Currently with Monsanto Research Corporation-Mound, Miamisburg, Ohio.

$\dagger$ Mound is operated by Monsanto Research Corporation for the U.S. Department of Energy. The submitted manuscript has been authored by a contractor of the U.S. Government under Contract No. DE-AC04-76-DP00053. Accordingly, the U.S. Government retains a nonexclusive, royalty-free license to publish or reproduce the published form of this contribution, or allow others to do so, for U.S. Government purposes.
}

microcoated particles, ${ }^{3}$ was used in this work. Microcoating means having a uniform distribution of the copolymer on the PETN particles. Prior to microcoating, PETN exhibits inferior pourability and pelletization properties. However, after using the microcoating process, a free-flowing PETN powder results which has improved pellet strength without loss of ignition sensitivity. ${ }^{3}$

\section{EXPERIMENTAL}

The PETN powder used in this work was purchased from duPont. ${ }^{4}$ The vinylchloride/trifluorochloroethylene copolymer was purchased from Firestone Plastic Company; ${ }^{5}$ this copolymer is referred to as FPC-461. The PETN powder was dissolved in acetone and was then precipitated by the addition of water. This process recrystallizes PETN to remove impurities. PETN is then coated using the microcoating process. One-hundred gram $(100 \mathrm{~g})$ batches of 0.5 and $20 \mathrm{wt} \%$ coated PETN were made by following previously documented starved addition procedures. ${ }^{3}$

The copolymer and the 0.5 and $20 \mathrm{wt} \%$ coated PETN powders were then pressed, at room temperature, into pellets on an Instron. The pellets were pressed to $95 \%$ density in a mold to obtain dimensions of $19.0 \mathrm{~mm}$ (0.748 in) in diameter and $2.1 \mathrm{~mm}(0.083 \mathrm{in})$ in thickness. The copolymer, PETN, and coated PETN materials were pressed into pellets at $\sim 3515 \mathrm{~kg} \mathrm{~cm}^{-2}$ ( $50 \mathrm{~K} \mathrm{psi)}$. A ram speed of $5.0 \mathrm{~mm}(0.2 \mathrm{in})$ per minute was used, and the pellets were held at pressure for $60 \mathrm{~s}$ to assure uniform pelletization.

A Surface Science Laboratory XPS Spectrometer ${ }^{6}$ (Model SSX-100) was used. This instrument is a small 


\section{DISCLAIMER}

This report was prepared as an account of work sponsored by an agency of the United States Government. Neither the United States Government nor any agency Thereof, nor any of their employees, makes any warranty, express or implied, or assumes any legal liability or responsibility for the accuracy, completeness, or usefulness of any information, apparatus, product, or process disclosed, or represents that its use would not infringe privately owned rights. Reference herein to any specific commercial product, process, or service by trade name, trademark, manufacturer, or otherwise does not necessarily constitute or imply its endorsement, recommendation, or favoring by the United States Government or any agency thereof. The views and opinions of authors expressed herein do not necessarily state or reflect those of the United States Government or any agency thereof. 


\section{DISCLAIMER}

Portions of this document may be illegible in electronic image products. Images are produced from the best available original document. 
<smiles>CC(CO[N+](=O)[O-])C(C)(CO[N+](=O)[O-])CO[N+](=O)[O-]</smiles>

Figure 1. Structure of PETN.

spot size XPS analyzer; the analysis spot in this study was $300 \mu \mathrm{m}$. The excitation source was a monochromatic $\mathrm{Al}\left[\mathrm{K}_{\alpha}\right]$ line of $1486.6 \mathrm{eV}$. An $\mathrm{x}$-ray wattage of $50 \mathrm{~W}$ (10 kV and $5 \mathrm{~mA}$ ) was used in accumulating the data. Samples were placed in front of the photon beam; survey and high resolution scans were taken. A typical time to record all XPS data was 30 min per sample. An electron charge neutralizer of $12 \mathrm{~V}$ was required to neutralize each sample. No change in the spectra could be detected after several successive $30 \mathrm{~min}$ runs for a total of $12 \mathrm{~h}$ radiation; this shows that the copolymer and PETN were not dissociated by the $\mathrm{Al}\left[\mathrm{K}_{\alpha}\right]$ photons.

The surface compositions were determined on three different areas of the specimen. This was accomplished by moving the sample, such that, a new area was being irradiated and analyzed. The intensities of the three scans were averaged. The atomic percents were reproducible to approximately $\pm 10 \%$. The atomic percent was determined by: first, setting a linear background under each peak; second, measuring the counts above the background per channel; third, summing the counts in all the channel's under the peak; fourth, dividing the summed peak intensity by the Scofield ${ }^{7}$ sensitivity factor (modified intensity); and finally, calculating the percent of the modified intensity (atomic percent).

A Kratos ${ }^{8}$ ISS System (Model \#535) connected to a DS-800 Data System was used for accumulating and recording the ISS spectra of the copolymer, PETN, and coated PETN samples. The analyzer is a cylindrical mirror with a scattering angle of $138^{\circ}$. The system was pumped to pressures of $10^{-9}$ torr with an ion pump $\left(110 \mathrm{l} \mathrm{s}^{-1}\right)$ and a turbomolecularpump $\left(330 \mathrm{l} \mathrm{s}^{-1}\right)$. Samples were mounted on a carousel and placed into the vacuum chamber. ${ }^{3} \mathrm{He}^{+}$was used as the scattering ion when recording ISS spectra. Samples were bombarded with $1.8 \mathrm{keV}{ }^{3} \mathrm{He}^{+}$ions at a $100 \mathrm{nA}$ ion current which was

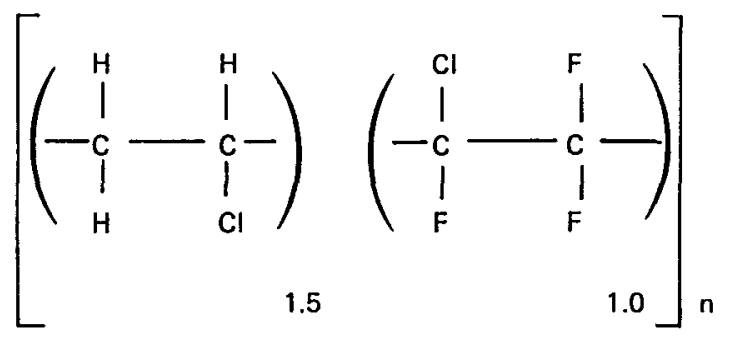

Figure 2. Structure of the copolymer. (a)

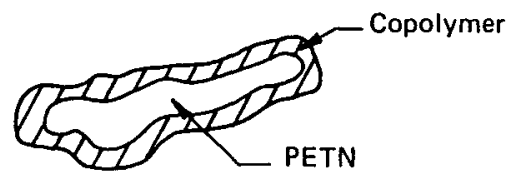

(b)

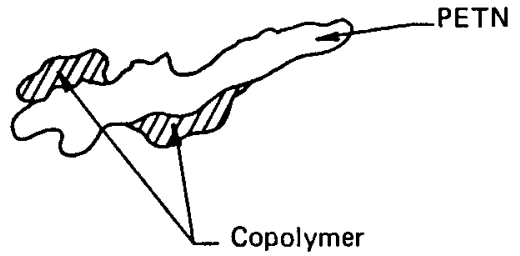

Figure 3. Illustration of proposed models for the microcoating of PETN: (a) Model I is a totally coated PETN particle and (b) Model II is a partially coated PETN particle.

rastered over $1 \mathrm{~cm}^{2}$. A channel step size of $\Delta\left(E_{1} / E_{0}\right)=$ 0.005 (where $E_{1}=$ scattered primary ion and $E_{0}=$ primary ion energy) and a helium pressure of $1 \times 10^{-7}$ torr were used in recording all scans. ISS spectra were recorded within $10 \mathrm{~s}$; however, acquisitional times were $600 \mathrm{~s}$ for survey scans and $24 \mathrm{~s}$ for regional scans. Within $24 \mathrm{~s}$ of counting, no detectable decomposition was observed in the copolymer, PETN, and coated PETN samples.

\section{RESULTS AND DISCUSSION}

The molecular structure of pentaerythritoltetranitrate (PETN), $\mathrm{C}\left(\mathrm{CH}_{2}\right)_{4}\left(\mathrm{ONO}_{2}\right)_{4}$, is shown in Fig. 1. PETN is an organic energetic material. The important part of the PETN compound is the nitrate $\left(-\mathrm{ONO}_{2}\right)$ functional group, which gives PETN its explosive properties.

The molecular structure of the copolymer $\left[-\left(\mathrm{CH}_{2} \mathrm{CHCl}\right)_{1.5}\left(\mathrm{CF}_{2} \mathrm{CFCl}\right)_{\overline{1.0}}\right]_{n}$, is shown in Fig. 2. This copolymer was chosen for this work because it has been used on plastic bonded explosives as well as other explosives in the industry. ${ }^{9,10}$ The chlorine and fluorine in the copolymer structure are easily detectable in XPS and ISS, making the copolymer $(\mathrm{Cl}, \mathrm{F})$ distinguishable from $\operatorname{PETN}(\mathrm{N}, \mathrm{O})$.

\section{Proposed models for the microcoating process}

In order to discuss the results of microcoating (on the surface chemistry), two general models were proposed. These two models include: (a) particles completely coated by the copolymer (Model I) and (b) particles only partially coated (Model II). These models are illustrated in Figs $3(a, b)$. These general models aid in understanding changes in the surface and interfacial chemistry of the copolymer and PETN before and after microcoating.

\section{XPS and ISS spectral results relative to the proposed models}

The XPS and ISS survey spectra of pellets are shown in Figs 4 and 5, respectively. In these figures, spectra 


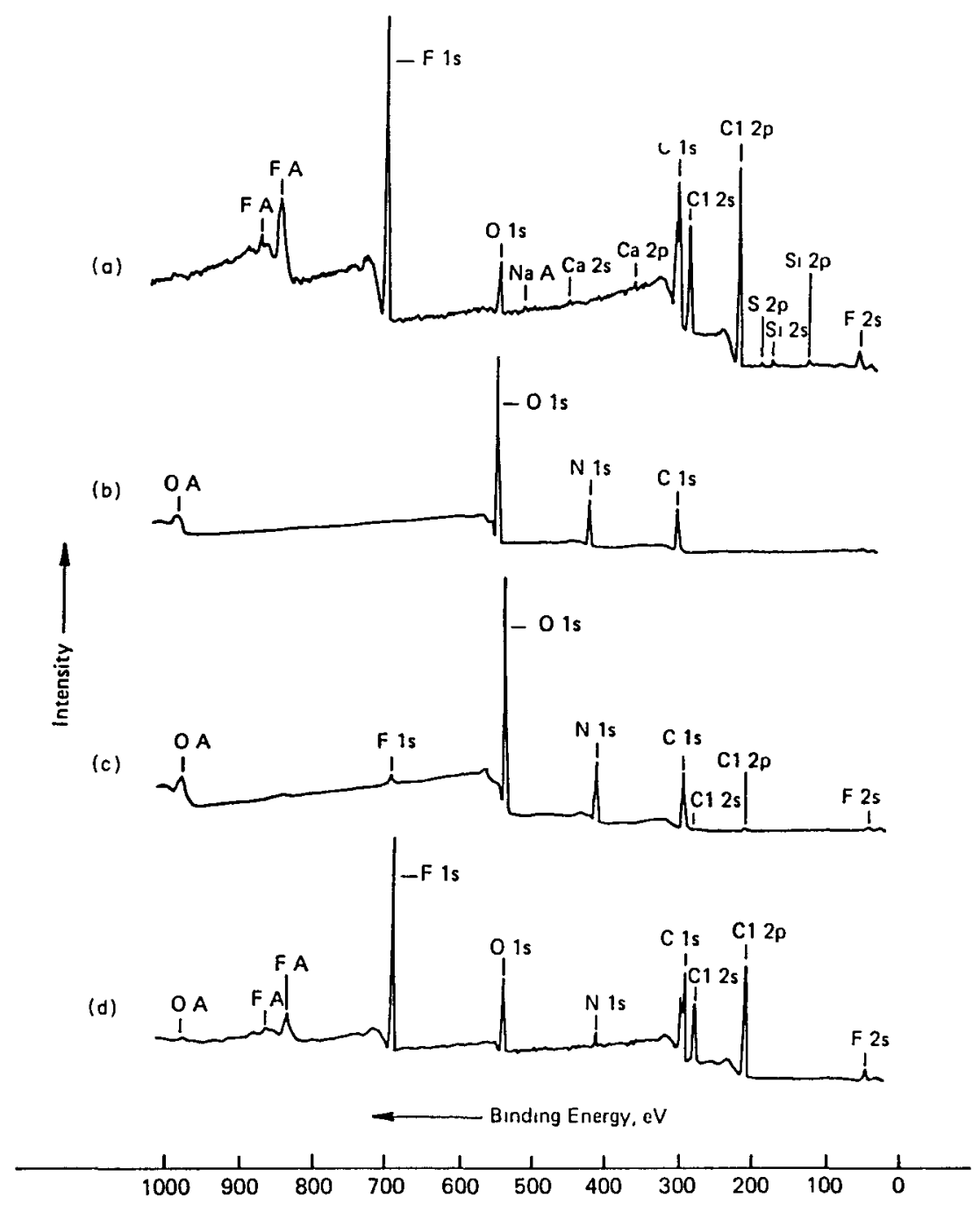

Figure 4. X-ray photoelectron spectroscopy survey spectra showing the characteristic peaks of (a) the copolymer, (b) PETN, (c) 05 wt \% coated PETN, (d) 20 wt\% coated PETN, pellet samples

have been recorded for (a) the copolymer, (b) PETN, (c) $0.5 \mathrm{wt} \%$ coated PETN, and (d) $20 \mathrm{wt} \%$ coated PETN. These data show carbon, nitrogen, and oxygen characteristic of PETN and carbon, fluorine, and chlorine characteristic of the copolymer. The XPS spectra showed no sample degradation after $12 \mathrm{~h}$ of exposure to $\mathrm{x}$-ray radiation, whereas, the ISS spectra show sample degradation after only $600 \mathrm{~s}$ of ion beam exposure.

The XPS spectral results for the powder and pellet samples (as atomic percent) are summarized in Table 1. As can be seen from this table, there is no significant difference between the powders and pellets for each sample (the copolymer, PETN, $0.5 \mathrm{wt} \%$ coated PETN, and $20 \mathrm{wt} \%$ coated PETN). These data will be used later in the paper to calculate the copolymer thickness.

In order to eliminate ion beam damage, ISS spectra of the characteristic lines for oxygen (PETN) and fluorine (of the copolymer) were recorded within $24 \mathrm{~s}$. The spectra for the pellets are shown in Figs $6(a-d)$, and the spectra for the powders are shown in Figs 6(e-h). The fluorine to oxygen signal intensities are higher for both the 0.5 and $20 \mathrm{wt} \%$ coated PETN samples of

\begin{tabular}{|c|c|c|c|c|c|}
\hline & $\mathrm{C} 1 \mathrm{~s}$ & $\mathrm{~N}$ is & $01 \mathrm{~s}$ & $\mathrm{Cl} 2 \mathrm{p}$ & F1s \\
\hline \multicolumn{6}{|l|}{ Copolymer } \\
\hline Powder ${ }^{a}$ & 530 & - & 38 & 160 & 270 \\
\hline Pellet $^{b}$ & 500 & - & 40 & 180 & 260 \\
\hline \multicolumn{6}{|l|}{ PETN } \\
\hline Powder & 290 & 180 & 530 & - & - \\
\hline Pellet $^{c}$ & 300 & 180 & 520 & - & - \\
\hline \multicolumn{6}{|c|}{05 wt $\%$ coated PETN } \\
\hline Powder & 340 & 160 & 460 & 18 & 22 \\
\hline Pellet & 330 & 170 & 480 & 12 & 12 \\
\hline \multicolumn{6}{|c|}{$20 w t \%$ coated PETN } \\
\hline Powder ${ }^{d}$ & 410 & 33 & 130 & 150 & 260 \\
\hline Pellet & 490 & 29 & 99 & 180 & 200 \\
\hline \multicolumn{6}{|c|}{ 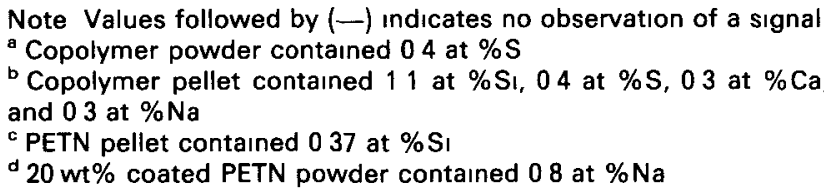 } \\
\hline
\end{tabular}




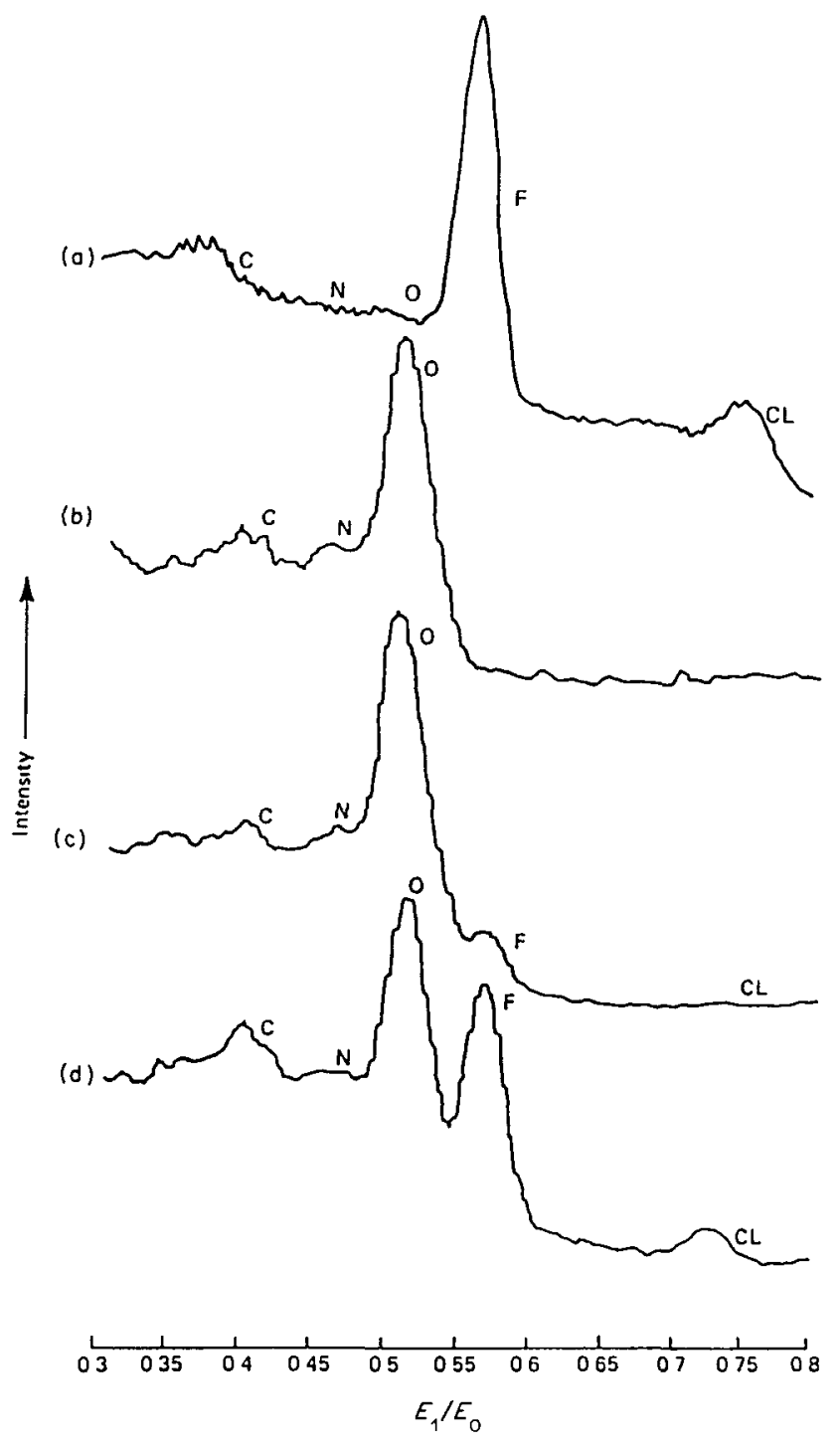

Figure 5. Ion scatterıng spectroscopy survey spectra showing the characteristic peaks of (a) the copolymer, (b) PETN, (c) $05 \mathrm{wt} \%$ coated PETN, and (d) 20 wt $\%$ coated PETN, pellet samples

Figs 6(a-d) as compared to their counterparts in Figs 5(a-d). Lower fluorine/oxygen ratios noted in Fig. 5 are due to ISS beam damage that can decompose or sputter the copolymer from PETN.

Ion beam damage on the copolymer, PETN, and coated PETN pellets was extensively studied showing no detectable degradation with $24 \mathrm{~s}$ of irradiation. ${ }^{11}$ Therefore, Fig. 6 represents ISS data with no ion beam damage. ISS data of the spectra for the powders and pellets from Fig. 6 are summarized in Table 2.

The data for the oxygen and fluorine signals were not normalized to the oxygen level in pure PETN and the fluorine level in pure copolymer. In order to normalize for differences in scattering probability from an element, the oxygen and fluorine signals were adjusted by the use of sensitivity factors. ${ }^{12}$ This information has been integrated into Table 2. Data are given as the area under each of the fluorine and oxygen peaks as ratioed to the sum of the two signals. These data will be used to determine the correct model for microcoating and in the next section to calculate the copolymer thickness.
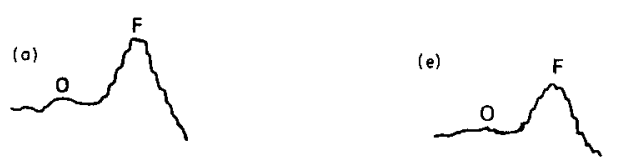

(b)

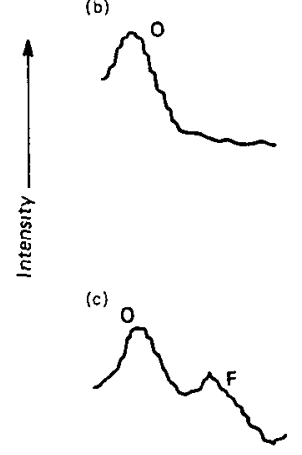

(f)

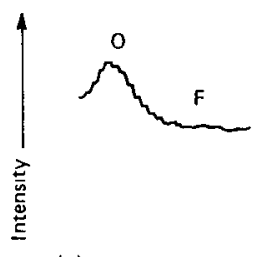

(g)
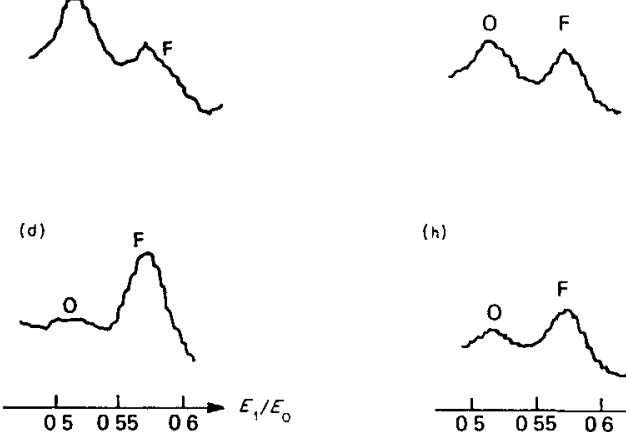

(n)

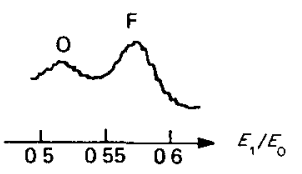

Figure 6. ISS elemental spectra of oxygen and fluorine for pellet samples of (a) the copolymer, (b) PETN, (c) $05 \mathrm{wt} \%$ coated PETN, and (d) $20 \mathrm{wt} \%$ coated PETN, and for powder samples of (e) the copolymer, (f) PETN, (g) $05 \mathrm{wt} \%$ coated PETN, and (h) $20 \mathrm{wt} \%$ coated PETN, recorded withın $20 \mathrm{~s}$ and without sputtering or ion beam degradation

The ISS spectrum of Fig. $6(\mathrm{~g})$ indicates that oxygen is present on the surface of the $0.5 \mathrm{wt} \%$ coated PETN powder. The data shows that PETN is present on the particle surface of the $0.5 \mathrm{wt} \%$ coated PETN powder. This result is in support of Model II (a partially coated particle). If Model I (totally coated particle) had been the case, only the copolymer element $(F)$ and not the PETN element $(O)$ would appear in the spectrum. The ISS data of the powder and pellet with $0.5 \mathrm{wt} \%$ copolymer shows the pellet to have less copolymer than the powder. This suggests that the copolymer is being redistributed during pelletization, allowing more PETN to be exposed on the surface of the pellet. Since PETN is

Table 2. Oxygen and fluorine ISS signals ratioed to the sums for 0.5 and $20 \mathrm{wt} \%$ powder and pellet PETN samples

\begin{tabular}{|c|c|c|c|c|c|}
\hline & \multirow{2}{*}{$\begin{array}{l}\text { Sensitivity } \\
\text { factor }\end{array}$} & \multicolumn{2}{|c|}{ Powder } & \multicolumn{2}{|c|}{ Pellet } \\
\hline & & $05 w t \%$ & $20 w t \%$ & $05 w t \%$ & $20 w t \%$ \\
\hline$P=\frac{O}{O+F} \times 100$ & 10 & 66 & 37 & 73 & 27 \\
\hline$C=\frac{F}{O+F} \times 100$ & 13 & 34 & 63 & 27 & 73 \\
\hline $\begin{array}{l}\% \text { PETN at sur } \\
\% \text { Copolymer } \\
\text { Oxygen } \\
\text { Fluorine }\end{array}$ & face & & & & \\
\hline
\end{tabular}


on the surface after pressing, the microcoating of a $0.5 \mathrm{wt} \%$ pellet can be explained by Model II.

XPS and ISS results indicate that the $20 \mathrm{wt} \%$ coated powder and pellet have more copolymer present on the surface of the PETN particles than the $0.5 \mathrm{wt} \%$ coated sample. In the case of the $20 \mathrm{wt} \%$ specimen, oxygen of PETN is seen on the powder but not on the pellet, and the ratio of fluorine to the sum (oxygen plus fluorine) is less for the powder than the pellet. Thus, in making $20 \mathrm{wt} \%$ microcoated PETN powder, an incompletely coated PETN (Model II) is created; however, the copolymer is redistributed during pelletization resulting in completely coated PETN (Model I).

\section{Calculation of copolymer thickness}

In light of Model II, the copolymer thickness can be computed for microcoated PETN by using a modified XPS expression which includes ISS data. The general XPS expression ${ }^{13}$ of $I=I_{0} \mathrm{e}^{-d / \lambda \sin \phi}$ can be modified in order to write equation (1):

$$
d=(\bar{\lambda} \sin \phi) \ln \frac{C \times I_{\mathrm{PETN}}^{*}}{100 \times I_{\mathrm{PETN}}-P \times I_{\mathrm{PETN}}^{*}}
$$

where $d$ is the average copolymer thickness, $I_{\mathrm{PETN}}$ is the intensity of an XPS photoelectron line from PETN which has been coated with the copolymer, $I_{\text {PFTN }}^{*}$ is the intensity of an XPS photoelectron line from PETN $(d=$ $0), \bar{\lambda}$ is the mean free path of $\mathrm{N} 1 \mathrm{~s}$ photoelectron line of PETN, $C$ is the percentage of copolymer observed in the ISS spectrum, $P$ is the percentage of PETN observed in the ISS spectrum, $\phi$ is the photoelectron take off angle measured from the horizontal surface. In this study $\phi=36^{\circ}$. Since a short counting time is required to avoid ISS sample degradation, the maximum amount of the copolymer mixed with PETN is $25 \%$; therefore, the limits for equation (1) were chosen to be $20<C<80$ and $20<P<80$.

In order to measure $I_{\text {PETN }}$ and $I_{\text {PETN }}^{*}$, the N 1 s photoelectron line (1100 eV kinetic energy) was used to monitor PETN in the XPS spectra. The mean free path $(\lambda)$ was taken from a plot of $\lambda$ versus electron energy and was determined to be $15 \AA .{ }^{14,15}$ This path length is the statistical sum of the $\mathrm{N}$ ls photoelectron which has traveled through PETN plus FPC. The percentage of the copolymer $(C)$ and the percentage of PETN $(P)$ on the surface have been measured from ISS data for $0.5 \mathrm{wt} \%$ powder and found to be 34 and 66 , respectively (from Table 2). Calculation of the average copolymer thickness was found to be $10 \AA$ in the coated regions for $0.5 \mathrm{wt} \%$ PETN powder. Equation (1) becomes impossible to use when $C$ is less than $20 \%$ of $P$. The copolymer thickness also becomes difficult to calculate as $d$ approaches $3 \lambda$.

An accurate determination of $d$ depends primarily on knowing the true value of $\lambda$ and on having a smooth uniform PETN surface. A value of $15 \AA$ was chosen for $\lambda$ from the literature. ${ }^{14.15}$ Often error in determining $\lambda$ is quoted to be $\pm 15 \% .^{1617}$ The PETN powder used in this study is a very irregular, rough, needle-like, parallel piped with an average length of $200 \mu \mathrm{m} .{ }^{18}$ Due to the needle-like structure of PETN, photoelectrons from many particles are being accepted at any one time during XPS analysis. The roughness and irregularity of the
PETN surface implies that $\phi$ will not remain a constant $36^{\circ}$; therefore, $d$ will vary throughout the sampling area. Although $\phi$ varies over the analyzed area, equation (1) can nevertheless be used to calculate an average value for the copolymer thickness.

\section{Bonding between the copolymer and PETN}

In addition to establishing the model and determining the copolymer thickness, the bonding of microcoated PETN was also examined. By measuring the XPS binding energy to $\pm 0.2 \mathrm{eV}$, the chemical bonding in the copolymer, PETN, and coated PETN can be determined. The $\mathrm{N} l s, \mathrm{O} l s, \mathrm{Fls}$, and $\mathrm{Cl} 2 \mathrm{p}$ binding energies were measured for all the powder and pellet samples. These data are illustrated in Figs 7(a-d) through 10(a-d).

Table 3 summarizes the results of the binding energies. The binding energy of nitrogen in PETN and coated PETN samples is $408.3 \mathrm{eV}$. This is characteristic of a nitrogen atom bound to three oxygen atoms such as in the nitrate linkage. ${ }^{19}$ More importantly, is the fact that the nitrogen is the same (to within $\pm 0.2 \mathrm{eV}$ ) for all samples. This indicates that during microcoating, nitrogen did not change in oxidation state. This is also true of the oxygen from PETN and the fluorine and chlorine from the copolymer. Since the nitrogen, oxygen, fluorine, and chlorine did not show binding energy changes, it can be concluded that both the copolymer and PETN are chemically unchanged during microcoating. Therefore, the bonding between the copolymer and PETN must involve either a mechanical attachment of the copolymer to the PETN particle or a weak van der Waals force.

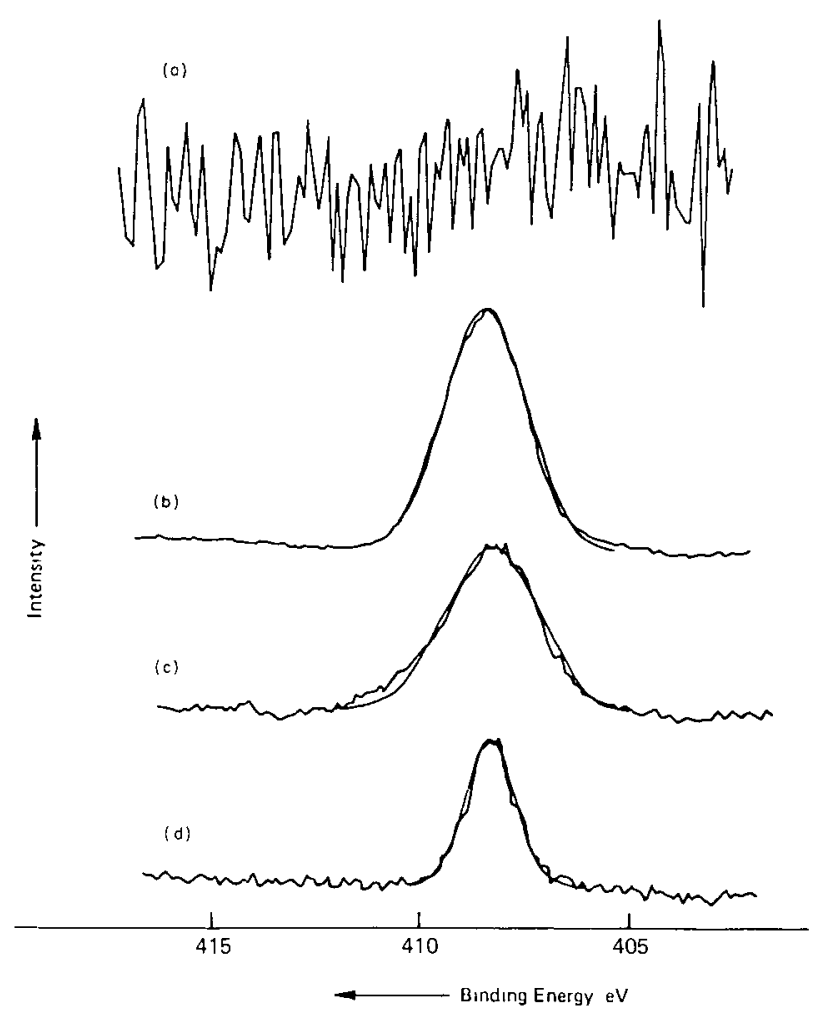

Figure 7. $\mathrm{N}$ 1s $\mathrm{x}$-ray photoelectron spectroscopy high resolution spectra for (a) the copolymer, (b) PETN, (c) 05 wt \% coated PETN, and (d) 20 wt \% coated PETN, pellet samples showing no change in binding energy 


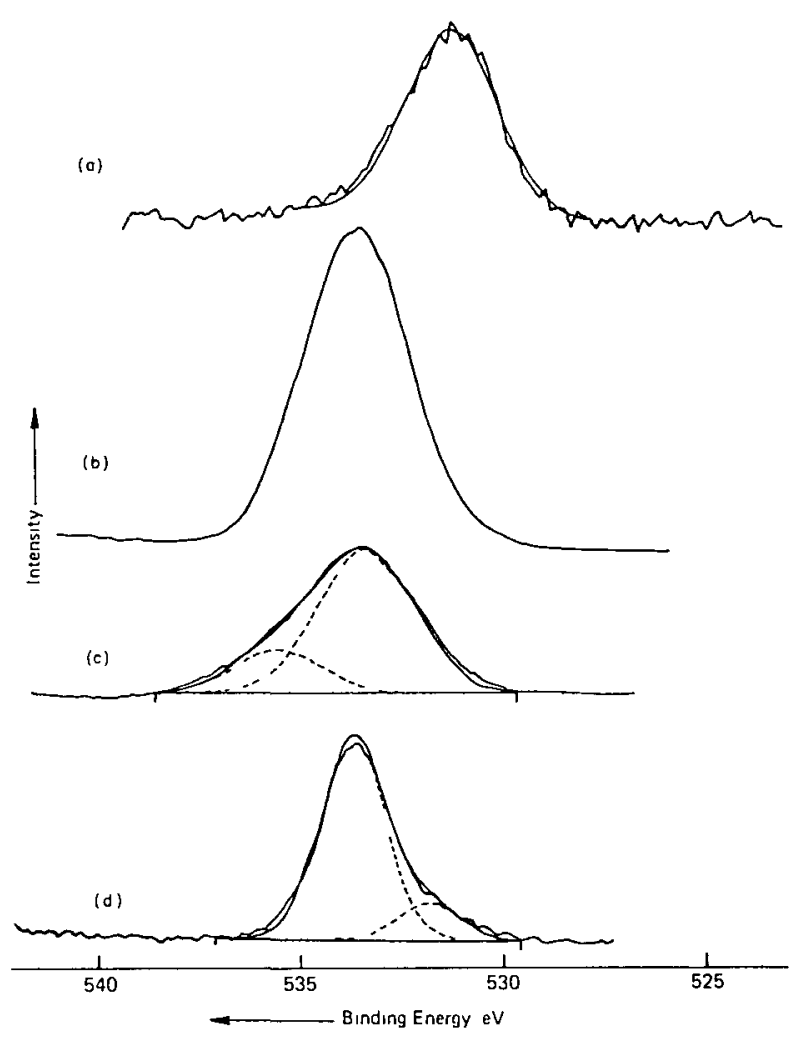

Figure 8. $O$ is $x$-ray photoelectron spectroscopy high resolution spectra for (a) the copolymer, (b) PETN, (c) 05 wt\% coated PETN, and (d) 20 wt \% coated PETN, pellet samples showing no change in binding energy

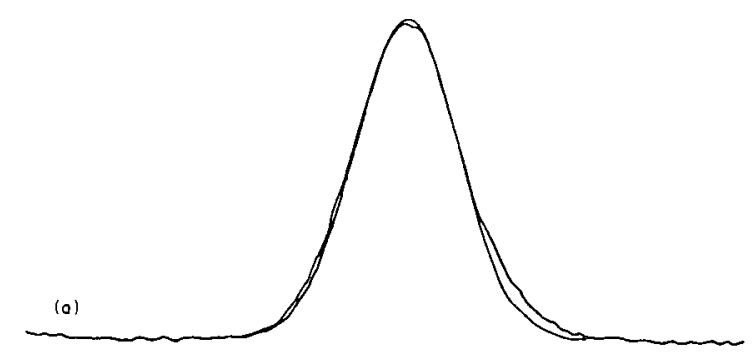

(b) No Spectrum

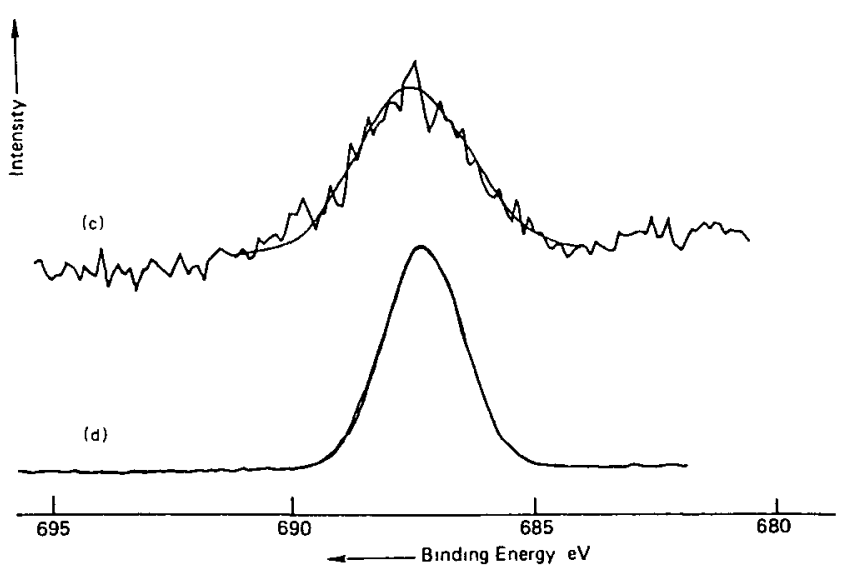

Figure 9. F 1s x-ray photoelectron spectroscopy high resolution spectra for (a) the copolymer, (b) PETN, (c) 05 wt \% coated PETN, and (d) $20 \mathrm{wt} \%$ coated PETN, pellet samples showing no change in binding energy

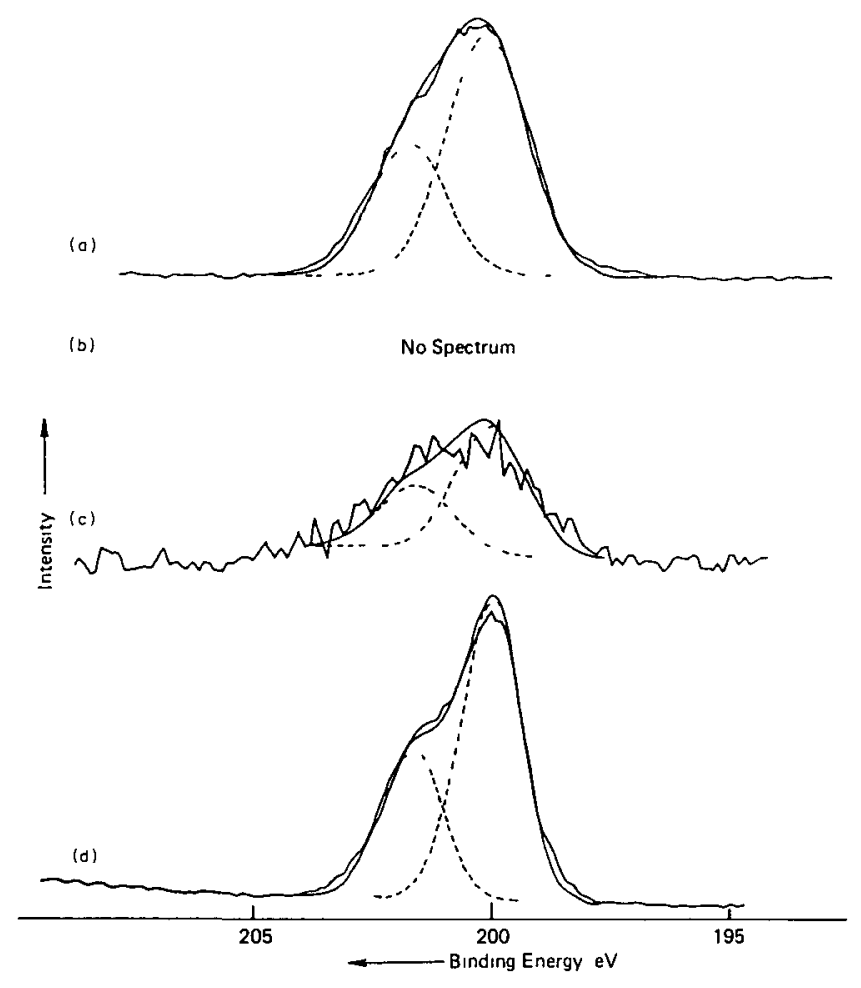

Figure 10. $\mathrm{Cl} 2 \mathrm{p} x$-ray photoelectron spectroscopy high resolution spectra for (a) the copolymer, (b) PETN, (c) 05 wt \% coated PETN, and (d) 20 wt \% coated PETN, pellet samples showing no change in binding energy

By examining the two proposed models and the XPS and ISS results, it appears that the bonding between the copolymer and PETN is mechanical. This is believed to be true because of the high electronegativity of the fluorine and chlorine of the copolymer and the oxygen of PETN. These electronegative groups prevent the attractive forces that are necessary for a van der Waals bond to occur.

The mechanical bond implies that the copolymer grabs onto the PETN particles at irregularities in the surface. Figure 11 illustrates how the mechanical bond between the copolymer and a PETN particle might occur.

Table 3. Summary of binding energies in $\mathrm{eV}$ from the XPS spectra for the copolymer, PETN, and coated PETN powders and pellets

\begin{tabular}{|c|c|c|c|c|c|}
\hline & $C 12 p$ & F is & $\mathrm{N} 1 \mathrm{~s}$ & $\begin{array}{l}\text { PETN } \\
\text { O 1s }\end{array}$ & $\begin{array}{c}\text { Coating } \\
01 \mathrm{~s}\end{array}$ \\
\hline \multicolumn{6}{|l|}{ Copolymer } \\
\hline Powder & 2000 & 6872 & & & 5312 \\
\hline Pellet & 2002 & 6870 & & & 5312 \\
\hline \multicolumn{6}{|l|}{ PETN } \\
\hline Powder & & & 4081 & 5335 & \\
\hline Pellet & & & 4085 & 5335 & \\
\hline \multicolumn{6}{|c|}{05 wt $\%$ coated } \\
\hline $\begin{array}{l}\text { Powder } \\
\text { Pellet }\end{array}$ & 2003 & 6874 & 4083 & \multicolumn{2}{|c|}{$5356 / 5335$} \\
\hline $20 w t \%$ co & & & & & \\
\hline Powder & 2001 & 6871 & 4081 & 5333 & 5314 \\
\hline Pellet & 2002 & 6874 & 4083 & 5337 & 5320 \\
\hline
\end{tabular}




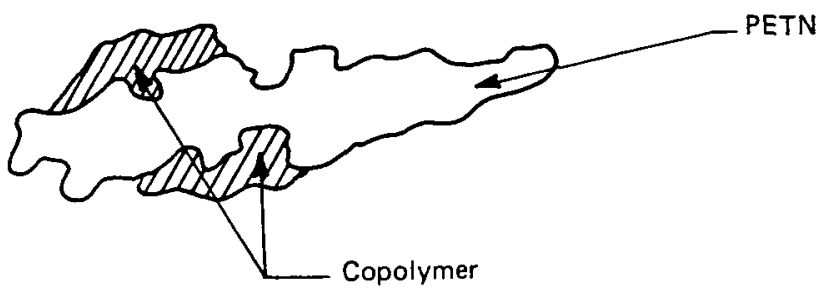

Figure 11. Mechanical bond between the copolymer and a PETN partıcle

\section{CONCLUSIONS}

Samples of a microcoated, highly energetic explosive were prepared. The explosive was pentzerythritoltetranitrate (PETN); the coating was a copolymer of vinylchloride/trifluorochloroethylene in a $1.5 / 1.0$ molecular ratio. A starved addition technique was used to microcoat PETN. X-ray photoelectron spectroscopy (XPS) and ion scattering spectroscopy (ISS) were used to study the surface and interfacial chemistry of the copolymer, PETN, and the 0.5 and $20 \mathrm{wt} \%$ coated PETN.

Two models were proposed to aid in discussing the microcoating of PETN, Model I depicted a totally coated particle, whereas, Model II illustrated a partially coated particle. XPS and ISS results support Model II for 0.5 and $20 \mathrm{wt} \%$ coated PETN powder. Results from the $0.5 \mathrm{wt} \%$ pellets are also in support of Model II, but the $20 \mathrm{wt} \%$ coated pellets were shown to be completely coated (Model I) due to copolymer redistribution during pelletization.

XPS and ISS measurements were recorded which allowed for the determination of an average copolymer thickness from equation (1). XPS and ISS showed the copolymer thickness to be thin. Results for $0.5 \mathrm{wt} \%$ coated powders and pellets were 10 and $6 \AA$, respectively.

The results of XPS binding energy measurements indicated no change in the surface chemistry of the copolymer and PETN after microcoating. Electronegativity considerations and these XPS results show the bond between the copolymer and PETN to be mechanical.

\section{REFERENCES}

1 M D Vannet, P S Wang, W E Moddeman and W C Bowling An $X$ ray Photoelectron Spectroscopy Study of the Compatibul ity of the Explosive PETN with Candidate Plastic Bonding Materials, Compatibility of Plastics and Other Materials with Explosives, Propellants, Pyrotechnics \& Processing of Explosives, Propellants and Ingredients Seminar, Hilton Head Island, South Carolina, p 92, 11-13 March 1985

2 P S Wang and T N Wittberg, J Energetıc Materıals, 15, 167 (1984)

3 M D Vannet and G L Ball, Utılization of Microencapsulation Coatıng Techniques to Achieve Prilling and Enhance the Pourability of PETN Explosive Powder, MLM-ML 84520003 , Monsanto Research Corporation, (1984)

4 PETN purchased from duPont, Louviers, Colorado

5 Copolymer purchased from Firestone Plastic Company (now Occidental Chemical Corporation, Pottstown, PA)

6 Surface Scıence Laboratory, Mountaın View, Calıfornıa

7 J H Scofield J Electron Spectrosc , 8, 129 (1976)

8 Kratos, Ramsey, New Jersey

9 T R Gibbs and A Popolato, (eds), LASL Explosive Property Data, p 100, University of Calıfornıa Press (1980)

10 B M Dobratz, LLNL Explosives Handbook Properties of Chemical Explosives and Explosive Stimulants, UCRL-52997, Distribution Category UC-45, p 1987, Lawrence Livermore National Laboratory (March 16, 1984)
11 W E Moddeman, C M Worley and W C Bowling, Photon Decomposition of Energetıc Materia/s, to be publıshed

12 E Taglauer and W Helland, Appl Phys Letters, 24, 437 (1974)

13 K Siegbahn, C Nordlıng, A Fahlman, R Noŕdberg, K Hamrın, $\mathrm{J}$ Hedman, $\mathrm{G}$ Johnansson, T Bergmark, S Karlsson, I Lindgren, B Lindberg, ESCA Atomic, Molecular and Solid State Structure Studied by Means of Electron Spectroscopy, (Almquist and Wiksells Boktryckeri AB, Upsala (1967)

14 T A Carlson, Photoelectron and Auger Spectroscopy, p 264, Plenum Press, New York (1975)

15 W M Rıggs and M J Parker in A W Czanderna, ed, Methods of Surface Analysis, Volume 1 of Methods and Phenomena Their Applications in Science and Technology, p 108, Elsevier Scientific Publishing Co (1975)

16 J Szajman, J G Jenkins, R C G Leckey and J Liesegang, J Electron Spectros, Related Phenomena, 19, 393 (1980)

17 D T Clark and H R Thomas, J Polymer Science, 15, 2843 (1977)

18 C M Worley, Surface Characterizatıon of an Energetıc Material, Pentaerythritoltetranitrate (PETN), Having a Thin Coating Achieved Through a Starved Addition Microencapsulation Tech nique, Thesis submitted to Graduate Engıneerıng and Research, School of Engıneerıng, University of Dayton, Dayton, Ohıo (April 1985)

19 D T Clark, P J Stephenson, T J Lewis, and F S Baker, Polymer, 22, 1303 (1981) 